\title{
Генерация сверхимпульсов в условиях модуляционной неустойчивости
}

\author{
И.О. Золотовский" \\ Д.И. Семенцов, М.С. Явтушенко, Д.Г. Санников \\ Ульяновский государственный университет, Ульяновск, Россия \\ *E-mail: rafzol.14@mail.ru
}

DOI: 10.31868/RFL2020.103-105

Исследования эффекта модуляционной неустойчивости (МН) вызывают интерес, связанный с его фундаментальностью и с возможностью создания на его основе различных систем управления лазерным излучением [1-3], например, в новейших системах связи и в метрологии. В настоящей работе рассматривается преобразование квазинепрерывного оптического излучения в последовательность субпикосекундных импульсов, формируемых в результате развития $\mathrm{MH}$. Показано, что пиковая мощность этих импульсов может превышать мощность фонового излучения на несколько порядков.

Пусть в световоде вдоль направления $\mathrm{z}$ реализуется бегущая волна показателя преломления (БВПП) вида

$$
n(t, z)=n_{0}[1-m \cos (\Omega t-q z)],
$$

a также вводится слабо модулированный квазинепрерывный волновой пакет, временная огибающая которого задается соотношением:

$$
A(0, \tau)=\sqrt{P_{0}}\left[1+\zeta \cos \left(\Omega_{\text {mod }} \tau\right)\right] .
$$

В уравнениях введены обозначения: $\Omega, q=2 \pi / \Lambda, \Lambda$ - частота модуляции, волновое число и период пространственной неоднородности ПП соответственно; $m=\Delta n / n_{0}, \Delta n$ - глубина модуляции и максимальное изменение показателя преломления в БВПП; $v_{m}=\Omega / q$ - скорость перемещения БВПП; $P_{0}=\left|A_{0}\right|^{2}, \zeta$, $\Omega_{\text {mod }}-$ мощность, глубина модуляции и частота модуляции волнового пакета. Динамика волнового пакета в среде с БВПП в координатах бегущего времени $\tau=t-z / v_{g}$ описывается как [5]:

$$
\frac{\partial A}{\partial z}-i \frac{d_{2}}{2} \frac{\partial^{2} A}{\partial \tau^{2}}+\frac{d_{3}}{6} \frac{\partial^{3} A}{\partial \tau^{3}}+i R|A|^{2} A=i \beta m \cos [\Omega(\tau-\delta \tau)] A,
$$

где $v_{g}=(\partial \omega / \partial \beta)_{\omega_{0}}-$ групповая скорость волнового пакета, $d_{n}=\left(\partial^{n} \beta / \partial \omega^{n}\right)_{\omega_{0}}-$ дисперсионные параметры второго и третьего порядка $(n=2,3), R$ - параметр кубической (керровской) нелинейности, $\beta=n_{0} \omega / c-$ постоянная распространения волнового пакета в невозмущенном световоде, $c$ - скорость света в вакууме. Величина $\tau-\delta \tau=\tau-\left(v_{m}^{-1}-v_{g}^{-1}\right) z-$ временная отстройка, связанная с расстройкой групповой скорости импульса и скорости перемещения БВПП.

На рис. 1 представлена динамика развития МН и формирования из исходно непрерывной волны накачки одного из последовательности сверхимпульсов (СИ). Сценарий формирования СИ в результате развития $\mathrm{MH}$, описанный в работе [4], можно представить следующим образом: вначале происходит развитие индуцированной МН и формирование высокочастотной последовательности импульсов (бризеров) с частотой следования 


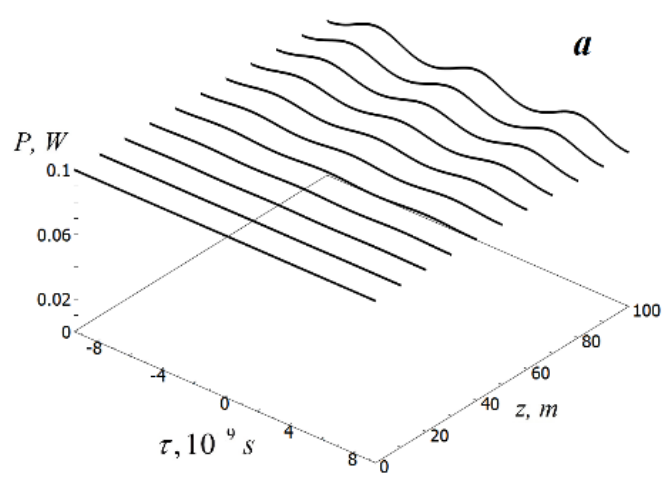

$b$
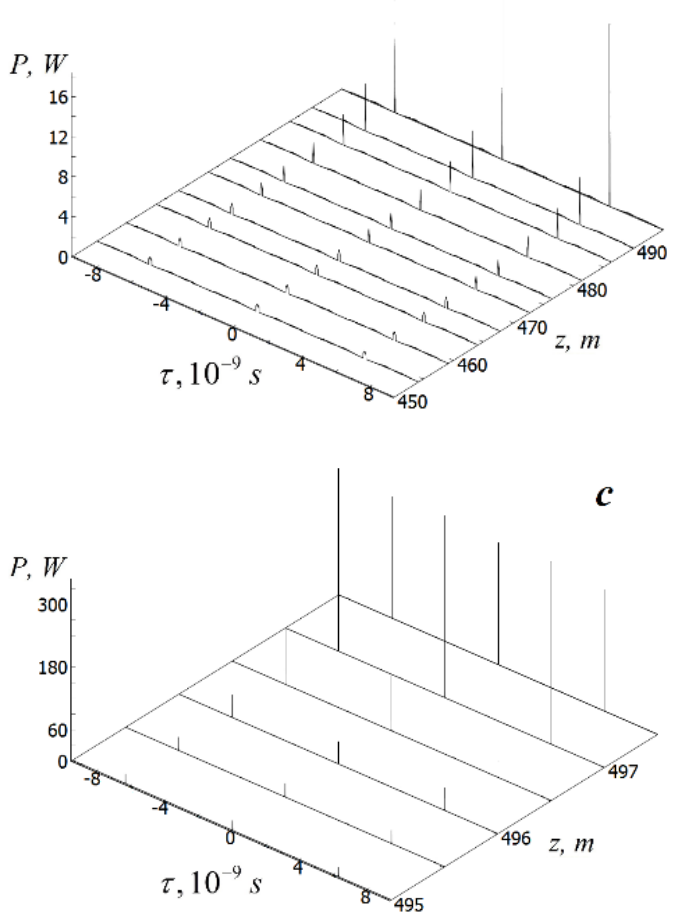

Рис. 1. Преобразование квазинепрерывной импульсов на различных длинах световода при следующих значениях параметров: $d_{2}=10^{-26} \mathrm{~s}^{2} / \mathrm{m}, d_{3}=0, R=10^{-3}(\mathrm{~W} \cdot \mathrm{m})^{-1}$, $P_{0}=0.1 \mathrm{~W}, \Omega_{r i}=10^{9} \mathrm{~s}^{-1}, \beta=10^{7} \mathrm{~m}^{-1}$, $\Delta n=10^{-4}, \Omega_{\text {mod }}=10^{12} \mathrm{~s}^{-1}, \zeta=10^{-3}$. волны в последовательность ультракоротких

$\Omega_{\max }=\sqrt{R_{e f} P_{0} /\left|d_{2 e f}\right|} \quad$ и длительностью отдельного импульса $\tau_{u} \approx 2 \pi / \Omega_{\max }$. Данный этап режима представлен $\mathrm{MH}$ на рис. 1 а. Следующий этап состоит в стягивании бризеров к областям максимума показателя преломления БВПП и формировании высокоэнергетического волнового пакета с энергией, пропорциональной $W_{s} \sim P_{0} / \Omega$. При этом виден взрывообразный характер формирования субпикосекундных импульсов. Так, для выбранных частоты и глубины модуляции исходно непрерывной волны с мощностью 100 мВт пиковая мощность генерируемых СИ значительно превосходит $P_{\max }>0,3 \kappa B m$, а их длительность составляет $\tau_{s} \sim P_{0} / \Omega P_{\max }, \quad$ т.е. стремится к величине, значительно меньшей пикосекунды. При этом пиковая мощность тем больше, чем меньше частота следования генерируемых импульсов (чем меньше частота их следования, тем больше энергия, собираемая СИ за счет когерентного сложения энергии бризеров, генерируемых за время $T=2 \pi / \Omega$ и стягивающихся в единый СИ). В работе показана сверхбыстрая (на длине менее 1 метра) «финальная» генерация субпкосекундных импульсов с киловаттными мощностями из последовательности сформированных маломощных импульсов для случая вращающихся волн.

При

исследовании квазинепрерывного волнового пакета в световоде с БВПП нами предполагалось, что выполняется условие равенства групповой скорости волнового пакета и скорости БВПП, т.е. $v_{g} \approx v_{m}=\Omega / q$. Наиболее простой реализацией таких условий можно добиться за счет взаимодействия непосредственно в световоде БВПП и поверхностной волны типа моды шепчущей галереи (так называемой, туннелирующей волны) [1]. В этом случае подобного рода волновые пакеты распространяются вдоль поверхности кварцевого цилиндрического световода по спирали с постоянным шагом. Среди особенностей таких спиральных волн важным является то, что их продольная 
(вдоль оси световода) групповая скорость может быть сколь угодно меньше скорости света.

Работа выполнена при поддержке Министерства Высшего образования и науки (проект №0830-2020-0009).

\section{Литература}

[1] V. P. Torchigin, Quantum Electron. 23(3), 235 (1993)

[2] B. B. Baizakov, V. V. Konotop, M. Salerno, J. Phys. B 35, 5105 (2002)

[3] A. M. Rubenchik, S. K. Turitsyn, M. P. Fedoruk, Opt. Express 18, 1380 (2010)

[4] D. A. Korobko, S. G. Moiseev, I. O. Zolotovskii., Opt.Lett. 40(20), 4619 (2015)

[5] I. O. Zolotovskii et al., JOSA B 36(10):2877 